\title{
Diagnosis and severity criteria for sinusoidal obstruction syndrome/veno-occlusive disease in pediatric patients: a new classification from the European society for blood and marrow transplantation
}

\author{
S Corbacioglu ${ }^{1,29}$, E Carreras ${ }^{2,29}$, M Ansari ${ }^{3,29}$, A Balduzzi ${ }^{4,29}$, S Cesaro ${ }^{5,29}$, J-H Dalle ${ }^{6,29}$, F Dignan ${ }^{7,29}$, B Gibson ${ }^{8,29}$, T Guengoer ${ }^{9,29}$, \\ B Gruhn ${ }^{10,29}$, A Lankester ${ }^{11,29}$, F Locatelli ${ }^{12,29}$, A Pagliuca ${ }^{13,29}$, C Peters ${ }^{14,29}$, PG Richardson ${ }^{15,29}$, AS Schulz ${ }^{16,29}$, P Sedlacek ${ }^{17,29}$, \\ J Stein ${ }^{18,29}$, K-W Sykora ${ }^{19,29}$, J Toporski ${ }^{20,29}$, E Trigoso ${ }^{21,29}$, K Vetteranta ${ }^{22,29}$, J Wachowiak ${ }^{23,29}$, E Wallhult ${ }^{24,29}$, R Wynn ${ }^{25,29}$, I Yaniv ${ }^{18,29}$, \\ A Yesilipek ${ }^{26,29}$, M Mohty $^{27,29}$ and P Bader ${ }^{28,29}$
}

The advances in hematopoietic cell transplantation (HCT) over the last decade have led to a transplant-related mortality below $15 \%$. Hepatic sinusoidal obstruction syndrome/veno-occlusive disease (SOS/VOD) is a life-threatening complication of HCT that belongs to a group of diseases increasingly identified as transplant-related, systemic endothelial diseases. In most cases, SOS/VOD resolves within weeks; however, severe SOS/VOD results in multi-organ dysfunction/failure with a mortality rate $>80 \%$. A timely diagnosis of SOS/VOD is of critical importance, given the availability of therapeutic options with favorable tolerability. Current diagnostic criteria are used for adults and children. However, over the last decade it has become clear that SOS/VOD is significantly different between the age groups in terms of incidence, genetic predisposition, clinical presentation, prevention, treatment and outcome. Improved understanding of SOS/NOD and the availability of effective treatment questions the use of the Baltimore and Seattle criteria for diagnosing SOS/VOD in children. The aim of this position paper is to propose new diagnostic and severity criteria for SOS/VOD in children on behalf of the European Society for Blood and Marrow Transplantation.

Bone Marrow Transplantation 2018) 53, 138-145; doi:10.1038/bmt.2017.161; published online 31 July 2017

\section{INTRODUCTION}

Major advances in hematopoietic cell transplantation (HCT) over the last decade have substantially decreased transplant-related morbidity and mortality; the expected mortality rate is now less than $15 \%{ }^{1}$ Hepatic veno-occlusive disease (VOD), also called sinusoidal obstruction syndrome (SOS; referred to as SOS/VOD hereafter) belongs to a group of conditions increasingly designated as transplant-related, systemic endothelial diseases, that include acute GvHD, engraftment syndrome and transplantassociated microangiopathy (TAM). SOS/VOD is an unpredictable and potentially life-threatening complication of $\mathrm{HCT}^{2,3}$ The primary insult in SOS/VOD is injury to both sinusoidal endothelial cells and hepatocytes in zone 3 of the hepatic acinus, ${ }^{4}$ triggered by several factors, such as the toxicity of the conditioning regimen, release of cytokines due to inflammation and engraftment, release of endotoxins, phenomena of alloreactivity, protein C anticoagulant pathway abnormalities and use of calcineurin inhibitors. Furthermore, monoclonal antibodies tagged with calicheamicin derivatives, such as gemtuzumab ozogamicin and inotuzumab ozogamicin, are triggers of SOS/VOD and onset can occur after Ab administration

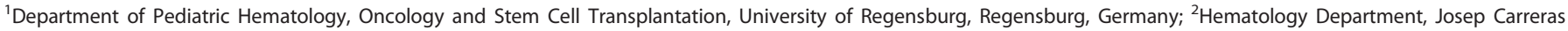

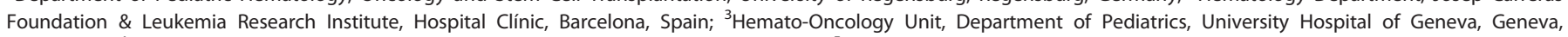

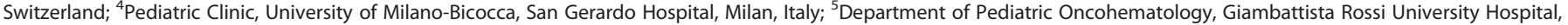

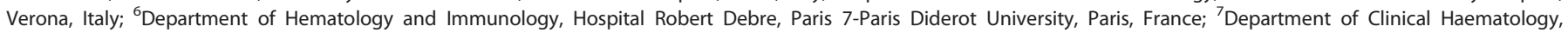

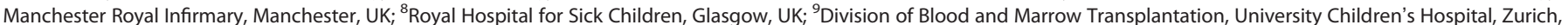

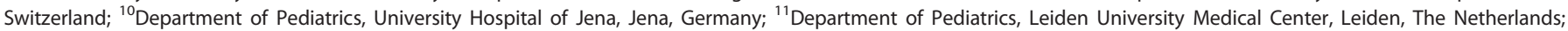

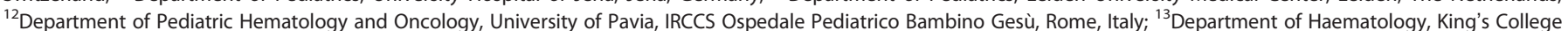

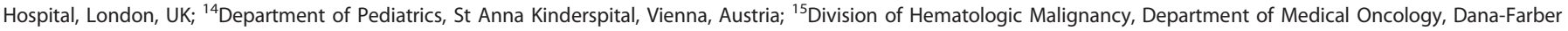

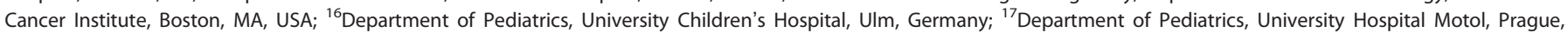

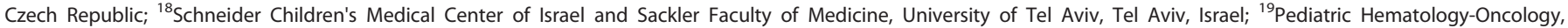

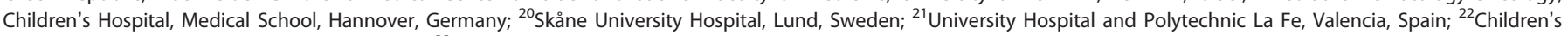

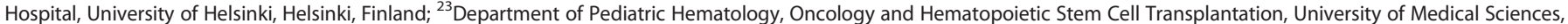

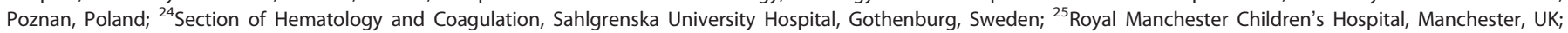

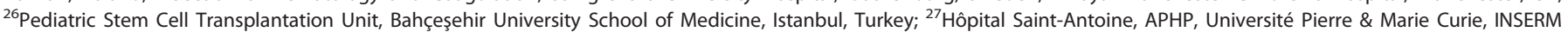

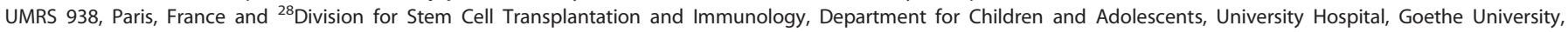

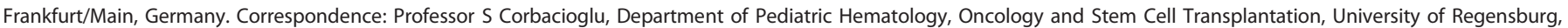
Franz-Josef-Strauss-Allee 11 Regensburg, 93053, Germany.

E-mail: selim.corbacioglu@ukr.de

${ }^{29}$ These authors contributed equally to this work.

Received 16 January 2017; revised 22 March 2017; accepted 29 May 2017; published online 31 July 2017 
Table 1. Major differences in hepatic SOS/VOD between adults and children

\begin{tabular}{|c|c|c|}
\hline Criteria & Children & Adults \\
\hline Clinical presentation & $\begin{array}{l}\text { - Late-onset SOS/VOD in } 20 \% \\
\text { - Anicteric SOS/VOD in } 30 \% \\
\text { - Hyperbilirubinemia, if present: } \\
\text { O Is frequently pre-existent } \\
\text { Occurs late during SOS/VOD } \\
\text { Is typical of severe SOS/VOD }\end{array}$ & $\begin{array}{l}\text { - Late-onset SOS/NOD is rare } \\
\text { - Anicteric SOS/VOD is rare }\end{array}$ \\
\hline $\begin{array}{l}\text { Need for proper assessment of ascites } \\
\text { and hepatomegaly }\end{array}$ & - High incidence of disease-related hepatomegaly and ascites pre-HCT & \\
\hline Treatment & $\begin{array}{l}\text { - DF for severe SOS/VOD with MOD/MOF was associated with better results } \\
\text { in children compared with adults }\end{array}$ & \\
\hline
\end{tabular}

alone or in subsequent $\mathrm{HCT}^{5-7}$ Particularly in children, SOS/VOD can also occur as a complication of conventional radio- and chemotherapy outside of the transplant setting. ${ }^{8-11}$ In addition to the triggers listed above, the risk of SOS/VOD is also dependent on patient-specific factors including genetic predisposition. ${ }^{12-14}$

While SOSNOD usually resolves within weeks in most patients, an estimated $30-60 \%$ of affected children may progress to multi-organ dysfunction/failure (MOD/MOF). ${ }^{4,15-17}$ In 20\% of cases, SOS/NOD develops more than 30 days after HCT. ${ }^{15,18,19}$ The clinical presentation of SOS/VOD consists of hepatomegaly, ascites and weight gain. SOS/VOD is essentially a clinical diagnosis in the absence of sensitive and specific biologic markers or imaging tools. $^{20-27}$ Two sets of diagnostic criteria for SOS/NOD have been used in clinical practice for the past three decades: $:^{15,17}$ the Baltimore $^{28}$ and Seattle criteria, ${ }^{29}$ the latter subsequently modified by a number of minor adjustments. ${ }^{15,30,31}$ Based on these criteria, the incidence of SOS/VOD ranges between 10 and 60\% in allogeneic $\mathrm{HCT}$ s with myeloablative conditioning (MAC) regimens, and between 5 and $30 \%$ in autologous $\mathrm{HCT}^{16}$ SOSNOD is seen significantly less often in patients who undergo reduced-intensity/ toxicity conditioning regimens. ${ }^{16,32-35}$ In children, the average incidence of SOS/VOD is $20 \%$, but in specific conditions can rise to $60 \%$. This incidence is higher than that reported in adults. ${ }^{15,36-38}$

Of note, the incidence of SOS/VOD differs by the criteria used for diagnosis, with up to a four-fold increased incidence of SOS/VOD observed between the Baltimore and Seattle criteria, respectively. ${ }^{15,16,34}$

The specific risk factors in children and the availability of effective licensed agents with favorable adverse-event profiles support the need for diagnostic and severity criteria specific to children.

Rationale for new diagnostic criteria: are children different from adults?

Currently the same diagnostic criteria for SOS/VOD are used in adults and children. This is despite evidence that the disorder differs significantly between children and adults in terms of incidence, genetic predisposition, clinical presentation and the outcomes of prevention and treatment (Table 1). Such differences suggest that the currently used criteria are no longer appropriate for the diagnosis of SOS/VOD in children. The aim of this position paper is to propose diagnostic and severity criteria for SOS/VOD in pediatric patients on behalf of the European Society for Blood and Marrow Transplantation (EBMT).

In terms of treatment, several studies over the last two decades have demonstrated that defibrotide (DF) is effective for the treatment and prevention of SOS/VOD when used in combination with supportive care. ${ }^{15,38-45}$ DF has European Medicines Agency authorization for the treatment of severe SOS/VOD and most recently received approval from the Food and Drug Administration in the USA. ${ }^{17,46}$ For treatment an international compassionate use program reported a superior outcome in children compared with adults. ${ }^{47}$ Early intervention with DF associated with a superior outcome was also shown first in children. ${ }^{48}$ The results of an expanded access Treatment-Investigational New Drug program, evaluating DF for the treatment of SOS/VOD, confirmed that earlier initiation of DF treatment was associated with significantly higher day +100 probability of survival. ${ }^{49}$

Risk factors and incidence in children

Risk factors can be divided into those directly related to the transplant, those related to patient characteristics including the underlying disease, and those related to hepatic factors. ${ }^{50}$ Factors directly related to the pre-transplant regimen and transplant include the use of ozogamicin-linked antibodies (gemtuzumab and inotuzumab) prior to transplantation, use of drugs for conditioning known to be toxic to the endothelium (such as high-dose busulfan (BU), single-fraction or high-dose fractionated $\left(\geqslant 12\right.$ Gray) TBI-based conventional MAC, ${ }^{16,33,35,51,52}$ and/or a combination of $\mathrm{BU}$ and cyclophosphamide and/or melphalan) and prior HCT. All of the above predispose children to SOS/VOD. ${ }^{15,19}$ Targeted IV BU has a predictable pharmacokinetic profile, ${ }^{53,54}$ but the measurement of BU serum levels is complicated by differences in methodology and lack of a reliable target range for safety, in particular when given as part of combination chemotherapy. Therefore, targeted IV BU cannot guarantee a reduced incidence of SOS/VOD. ${ }^{15,55-58}$

In summary, although treatment-related risk factors are similar between children and adults, the influence of individual risk factors related to patient characteristics (such as age of onset of primary disease and potentially genotype ${ }^{13}$ ) is greater in children than adults. 
A number of diseases, which are more common in childhood, can lead to an increased risk of SOS/VOD. For example, the reported incidence of SOS/VOD in infantile osteopetrosis is $60 \%{ }^{15,38,59}$ In congenital macrophage activation syndromes, such as familial hemophagocytic lymphohistiocytosis, Griscelli syndrome and X-linked lymphoproliferative disease, the reported incidence of SOS/VOD is $30 \%{ }^{15,60}$ Patients with thalassemia with hepatomegaly and high iron overload have a reported incidence of $30-40 \%{ }^{61-63}$ High-risk neuroblastoma is currently treated in Europe with high-dose chemotherapy and autologous HCT, usually after conditioning with $\mathrm{BU} / \mathrm{melphalan}$. Compared with the $<5 \%$ overall incidence of SOS/VOD following autologous HCT in adults, ${ }^{16,32}$ the reported $15-30 \%$ incidence in children with neuroblastoma is exceedingly high. ${ }^{15,37,58,64-66}$ SOS/VOD has been reported in children with Wilm's tumor, rhabdomyosarcoma and brain tumors given conventional chemotherapy, particularly in combination therapies including actinomycin D. ${ }^{9,67-69}$ Sickle cell disease may also potentially carry a high risk of SOS/VOD during transplant due to a combination of a systemic vasculopathy, iron overload/liver fibrosis and hepatitis. Above all, with a reported overall incidence of $30 \%,{ }^{15,70}$ infants are probably the largest group at risk of SOS/VOD. This might be attributable to the immaturity of the liver in this age group.

In summary, the overall incidence of SOS/VOD in children and infants is between $22 \%$ and $30 \%$, respectively, approximately two- to threefold higher than in adults. Under certain circumstances, the incidence can be as high as $60 \%$, indicating that SOS/VOD is more prevalent in childhood. ${ }^{15,36,37}$

\section{Clinical presentation}

The clinical presentation of SOS/VOD in children differs in several important respects from that in adults. The disease usually peaks around day +12 after HCT in both children and adults. However, while late-onset SOS/VOD is rare in adults, ${ }^{19,71,72}$ in children, $15-20 \%$ of SOS/VOD cases $^{15,36,37}$ present beyond day +30 , a time exceeding the 21- and 20- day limits specified by the Baltimore ${ }^{28}$ and Seattle criteria, ${ }^{29}$ respectively.

These sets of criteria ${ }^{31}$ also require a weight gain of 5 and $2 \%$, respectively. In children a weight gain of $2 \%$ can be of doubtful significance. In particular, in infants, rapid weight changes due to iatrogenic fluid overload or inaccurate measurements, including the weight of clothing and diapers, can easily falsify results. Therefore, the Seattle criteria have been modified to require a $5 \%$ weight gain in children to improve specificity. ${ }^{15}$ However a single weight measurement does not reflect the dynamics of this disease.

The original publication of the Seattle criteria refers to 'painful hepatomegaly' as a criterion, ${ }^{29}$ whereas the subsequent publication lists 'right upper quadrant pain' as an independent criterion. ${ }^{30}$ In children, assessment of right upper quadrant pain is difficult, particularly in infants and toddlers, making this a subjective criterion in a high-risk pediatric patient population.

The sine qua non Baltimore criterion is hyperbilirubinemia $\geqslant 2 \mathrm{mg} / \mathrm{dL}$, which is an apparently objective and investigatorindependent marker. However, anicteric SOS/VOD was observed in $32 \%$ of patients in the pediatric prevention trial, including those experiencing severe disease. ${ }^{15}$ This observation was confirmed in two independent publications, which reported an incidence of anicteric SOS/VOD of 30 and $29 \%$, respectively. ${ }^{73,74}$ Anicteric SOS/VOD seems to be particularly prevalent in children, although it is also seen in adults with late-onset SOS/VOD. ${ }^{18,19,75}$ Reflecting this, the new EBMT criteria for adults follow the Baltimore criteria of bilirubin $\geqslant 2 \mathrm{mg} / \mathrm{dL}$ for early-onset SOS/VOD ( $<21$ days), but omit hyperbilirubinemia as an obligatory criterion for late-onset SOS/VOD. ${ }^{50}$

Prompt diagnosis and early intervention are crucial in patients with SOS/VOD before they develop MOD/MOF with its associated high mortality rate. $^{34,49}$ Applying the Baltimore criteria for hyperbilirubinemia could mean that up to one-third of pediatric patients would currently fail to meet the diagnostic criteria of SOS/VOD and would therefore be excluded from timely and effective therapy. In terms of disease severity, hyperbilirubinemia is often a late finding in SOS/VOD, which reflects more advanced and perhaps irreversible hepatic injury, associated with a worse outcome. Naples et al. ${ }^{74}$ reported that the total treatment duration was longer and that the level of supportive care required was significantly higher in SOS/VOD patients with icterus compared with those without hyperbilirubinemia $(P=0.224$ and $P=0.0081$, respectively). In the pediatric prevention trial, the $60 \%$ incidence of MOD/MOF in patients who were diagnosed according to the Baltimore criteria was significantly higher than the 32\% incidence seen in patients without hyperbilirubinemia $(P=0.038){ }^{15}$ Carreras et al. reported on 845 allogeneic HCTs, where SOS/VOD was diagnosed using both the Seattle criteria, where bilirubin $\geqslant 2 \mathrm{mg} / \mathrm{dL}$ is not diagnostic prerequisite, and the Baltimore criteria, with a cumulative incidence of $13.8 \%(n=117)$ and $8.8 \%$ $(n=73)$, respectively. Of the 117 patients diagnosed according to the Seattle criteria, $37.6(n=44)$ did not develop hyperbilirubinemia and therefore did not fulfill the Baltimore criteria; none of them developed MOD/MOF or had severe VOD. All MOD/MOF cases occurred in the group that fulfilled the Baltimore criteria. ${ }^{34}$ In a Japanese meta-analysis, the overall survival (OS) between patients diagnosed according to the Seattle or Baltimore criteria differed substantially. ${ }^{35}$ Jones et al. ${ }^{28}$ reported that only 1 out of 25 patients with VOD with a serum bilirubin level higher than 15 $\mathrm{mg} / \mathrm{dL}$ survived. Finally many pediatric diseases, such as thalassemia, sickle cell disease, hemophagocytic lymphohistiocytosis, osteopetrosis and others, present with conjugated hyperbilirubinemia independently of HCT, so that a diagnostic limit of $2 \mathrm{mg} / \mathrm{dL}$ is inappropriate.

The specificity of the Baltimore and Seattle criteria have been reported to be 89 and $95 \%$, respectively, ${ }^{28,29}$ however, the sensitivity was low (56\%). ${ }^{76}$ With an average $30 \%$ incidence of anicteric SOS/VOD in children, the estimate on specificity should be revised.

The recently revised diagnostic criteria for adults considered the inclusion of transfusion-refractory thrombocytopenia (RT) as a diagnostic criterion; however, this was excluded owing to the difficulty in evaluating RT during the pancytopenic phase after $\mathrm{HCT}^{50}$ The current understanding of the pathophysiology of SOS/VOD is that a sustained and uncontrolled endothelial/ sinusoidal activation is the primary triggering event. There is ample evidence that consumptive thrombocytopenia and refractoriness to platelet transfusions, most probably due to uncontrolled endothelial activation, is a hallmark of SOS/VOD. ${ }^{28,71,77-81}$ As early as 1993, McDonald et al. ${ }^{30}$ noticed an increased transfusion requirement before the onset of liver disease, most markedly in severe SOS/VOD. In clinical practice, after the exclusion of alternative causes, such as sepsis, TAM and other causes of consumptive thrombocytopenia, and Ab-mediated thrombocytopenia, the need for daily, or even more frequent platelet transfusion justifies a high level of suspicion of SOS/VOD.

\section{Imaging techniques}

Hepatomegaly and ascites are two major diagnostic Seattle and Baltimore criteria, although the means of assessment have never been specified. Since publication of both sets of criteria there have been rapid advances in diagnostic imaging, such as computed tomography (CT), magnetic resonance imaging and ultrasonography (US). These objective tools can enable the accurate assessment of both liver size and the presence of ascites.

US is almost universally available, often as a bedside tool, and is therefore very useful for the confirmation of clinically suspected hepatomegaly and ascites. CT and magnetic resonance imaging 
Table 2. EBMT diagnostic criteria for hepatic SOS/VOD in children

- No limitation for time of onset of SOS/VOD

The presence of two or more of the following ${ }^{a}$

- Unexplained consumptive and transfusion-refractory thrombocytopenia ${ }^{\mathrm{b}}$

- Otherwise unexplained weight gain on three consecutive days despite the use of diuretics or a weight gain $>5 \%$ above baseline value

- 'Hepatomegaly (best if confirmed by imaging) above baseline value

- 'Ascites (best if confirmed by imaging) above baseline value

- Rising bilirubin from a baseline value on 3 consecutive days or bilirubin $\geqslant 2 \mathrm{mg} / \mathrm{dL}$ within $72 \mathrm{~h}$

Abbreviations: $\mathrm{CT}=$ computed tomography; $\mathrm{HCT}=$ hematopoietic cell transplantation; $\mathrm{MRI}=$ magnetic resonance imaging; $\mathrm{SOS} / \mathrm{VOD}=$ sinusoidal obstruction syndrome/veno-occlusive disease; US = ultrasonography. ${ }^{a}$ With the exclusion of other potential differential diagnoses. ${ }^{b} \geqslant 1$ weight-adjusted platelet substitution/day to maintain institutional transfusion guidelines. 'Suggested: imaging (US, CT or MRI) immediately before HCT to determine baseline value for both hepatomegaly and ascites.

can substitute for or complement US. Although both are less operator-dependent than US, their use is hampered by either exposure to radiation and/or the need for sedation in younger children. Furthermore, repetitive examinations to assess the dynamics of the disease are impractical and potentially harmful for immunocompromised children, as they would have to leave their protected environment, potentially exposing them to an increased risk of infection.

The diagnostic specificity of SOS/VOD has not been improved beyond hepatomegaly and ascites by the addition of hepatic artery resistive index, velocity of portal venous flow, increased periportal echogenicity and increased hepatic echotexture, as well as the assessment of gallbladder wall thickening. ${ }^{27,82,83}$

Measurement of the hepatic venous gradient pressure by cannulation of the jugular vein was demonstrated in adults to be a very accurate, but invasive, technique to confirm the diagnosis of SOS/VOD. ${ }^{75,84,85}$ Neither the efficacy nor safety of this procedure has been verified in children, therefore hepatic venous gradient pressure cannot be recommended as a tool for early diagnosis, particularly in infants and toddlers.

Doppler US assesses hepatic and portal vascular flow, pressure abnormalities and hepatic arterial early acceleration indices. Although they correlated best with HVPG, these techniques are subjective and very dependent on the experience of the operator. In addition, these findings, in particular portal venous flow reversal (hepatofugal flow), are either not consistently present or are a late finding, and might therefore be useful for the assessment of severity rather than early diagnosis. ${ }^{26,86-89}$ Most importantly, even in patients with severe and very severe SOS/VOD, hepatofugal flow can be absent, and should not be used as a criterion of exclusion. ${ }^{90}$

In summary, although serial clinical examination and weight monitoring remain the basic standard for assessing SOS/VOD, the most practicable imaging tool to confirm the clinical diagnosis of hepatomegaly and ascites is US. In general, baseline and serial measurements by any imaging tool are mandatory for early detection of any changes in liver size and/or presence of ascitic fluid. Similar to pre-existing hyperbilirubinemia, diseases, such as thalassemia, sickle cell disease, hemophagocytic lymphohistiocytosis or osteopetrosis and others, mostly transplanted during childhood, may present with pre-existing hepatomegaly and ascites before transplantation.

\section{New EBMT criteria for the diagnosis of SOS/VOD in children}

The proposed EBMT criteria for the diagnosis of SOS/VOD in pediatric patients are summarized in Table 2 . These criteria acknowledge the differences in various aspects of the disease between children and adults, and recognize the recent evidence of the superiority of early intervention. The proposals are based on reviews of the literature, and the experience and opinions of the authors. It is acknowledged that the proposed criteria should ideally be prospectively validated in clinical studies and tested in daily practice, with periodic reassessment to reflect changes in data and/or methodology.

As approximately one-fifth of the patients are diagnosed after 21 days post HCT, and reflecting the new EBMT criteria for adults, $^{50}$ there should be no time limit for the diagnosis of late-onset SOS/VOD also in children.

Given the early onset of consumptive and transfusion-refractory thrombocytopenia in children, consumptive RT, defined as the need for at least daily platelet transfusions after the exclusion of other obvious causes, is viewed as an early and sensitive sign of SOS/VOD.

In children, daily measurements of weight and abdominal circumference may suggest the need for further investigations to assess hepatomegaly and ascites. A weight gain beyond $2 \%$ in a single measurement, as required by the Seattle criteria, can be misleading in children. Instead, the dynamics of endothelial damage and associated third spacing is better reflected by consecutive measurements over several days. Therefore, the pediatric EBMT criteria require a weight gain on 3 consecutive days, excluding other plausible causes, in addition to refractoriness to diuretic treatment. An unexplained weight gain of at least $5 \%$, as required by the Baltimore criteria, will be retained.

Proper assessment of ascites and hepatomegaly and of their dynamics over time using radiation-free imaging techniques is recommended. This recommendation has the purpose of improving the sensitivity and specificity of the criteria, particularly in a patient population with a high prevalence of pre-existing ascites and hepatomegaly. For reasons of sensitivity and specificity, the decision should not be based on clinical examination only. A mandatory prerequisite is the comparability with a baseline examination. Therefore, the EBMT criteria suggest that the clinical diagnoses of ascites and hepatomegaly are verified with reproducible and objective diagnostic imaging tools. For the purpose of defining liver size and the amount of free abdominal fluid, US seems the most appropriate tool; CT and magnetic resonance imaging are acceptable but more complicated to perform in children.

As hyperbilirubinemia ( $>2 \mathrm{mg} / \mathrm{dL}$ bilirubin) in children is frequently either absent or found only in advanced-stage severe SOS/VOD ${ }^{73,74}$ and because many children have pre-existing hyperbilirubinemia related to their primary disease, this criterion is difficult to use. For these reasons, pediatric EBMT criteria recognize anicteric SOS/VOD as a frequent entity and consider hyperbilirubinemia as a non-mandatory criterion. Instead of a predefined level of hyperbilirubinemia in children, the new EBMT criteria require the bilirubin level to rise from an individual baseline on 3 consecutive days, after the exclusion of competing causes.

Transjugular liver biopsy provides histologic evidence of SOS/VOD, and is frequently used in adults. ${ }^{84,85}$ However, it is an invasive technique, difficult to perform in children and dangerous in patients with profound thrombocytopenia. In this respect, a recent study ${ }^{91}$ summarized a single institution experience on the 
safety and utility of liver biopsies after pediatric HCT. This study reported on 16 patients who received 18 liver biopsies. Five of these were by the transjugular route. Complications occurred after five biopsies, four of which were transjugular. The most common complication was hemorrhage. Two of these patients required transfer to the intensive care unit for procedure-related complications. ${ }^{91}$ This experience suggests that transjugular liver biopsies should be avoided in children.

New EBMT criteria for grading the severity of SOS/VOD in children The implementation of pediatric EBMT criteria for SOS/VOD offers the potential for early therapeutic intervention with effective and well-tolerated drugs, which may impact on the presentation, incidence of severity and outcome of SOS/VOD. Consequently, the implementation of severity criteria for children is mandatory. Chao et al. ${ }^{92}$ and Carreras et al. ${ }^{75}$ proposed a grading system for adults implementing the five categories from the CTCAE (Common Terminology Criteria for Adverse Events): grade $1=$ mild, grade $2=$ moderate, grade $3=$ severe, grade $4=$ very severe and grade $5=$ death, which was adopted in the new severity criteria for adults. $^{50}$ The proposed criteria for severity grading of SOS/VOD in pediatric patients are summarized in Table 3 .

Owing to the primarily endothelial/sinusoidal nature of the disease, elevated transaminases are not usually found in the early stages of SOS/NOD when primary hepatocytic toxicity, such as infections and drug toxicity, should be excluded. Rising transaminases after the diagnosis of SOS/VOD reflect hepatocyte failure and advanced-stage disease (CTCAE level 4). Glutamate dehydrogenase is a liver-specific enzyme with mitochondrial expression, particularly in the central, perivenular hepatocytes of the liver lobule (zone 3 of the hepatic acinus). As such, an elevation of glutamate dehydrogenase may reflect severe hepatocellular damage and could be considered a more reliable assessment of severity in SOS/VOD in the future.
Persistent RT for $>7$ days despite early therapeutic intervention represents severe disease. ${ }^{30}$

Bilirubin $\geqslant 2 \mathrm{mg} / \mathrm{dL}$ is associated with morbidity and a worse OS despite pre-emptive therapeutic intervention, ${ }^{15,73,74}$ and therefore defines severe SOS/VOD in children.

Ascites and third spacing during the course of SOS/VOD have been recognized as criteria of severity. This mirrors the Bearman criteria, according to which early onset or marked weight gain were considered diagnostic of severe SOS/NOD. ${ }^{79,93}$ A precise measurement of ascitic fluid is not possible, but the need for paracentesis to release abdominal pressure and alleviate respiratory distress is a criterion of severe SOS/VOD. Furthermore, repeated drainage of peritoneal fluid over a defined period is a sign of uncontrolled disease.

A combination of two of the following criteria: persistent ascitic drainage, persistent RT, sustained high levels of liver function indexes (transaminases, glutamate dehydrogenase) and bilirubin $\geqslant 2 \mathrm{mg} / \mathrm{dL}$ defines very severe SOS/VOD (CTCAE grade 4 ) and predicts for an increased risk of death and the need for prolonged treatment.

Similar to the severity criteria for adults, the kinetics of symptom presentation is critical to evaluating the severity of SOS/VOD in children. The combination of several of the SOS/VOD-related signs mentioned above, within $48 \mathrm{~h}$, is likely to lead to severe SOS/VOD. ${ }^{75,79,93}$ In particular, a doubling of the bilirubin level from an individual baseline within $48 \mathrm{~h}$ should be considered a sign of severe SOS/VOD.

Patients requiring replacement of coagulation factors after the established diagnosis of SOS/VOD are considered to suffer from consumptive coagulopathy associated with hepatic failure.

Severe SOS/NOD resulting in MOD/MOF, is characterized by pulmonary and/or renal dysfunction and/or encephalopathy. ${ }^{16,17}$ Any combination of organ failure in SOS/VOD classifies very severe disease.

\begin{tabular}{|c|c|c|c|c|}
\hline CTCAE & 1 & 2 & 3 & 4 \\
\hline $\mathrm{LFT}^{\mathrm{b}}$ (ALT, AST, GLDH) & $\leqslant 2 \times$ normal & $>2$ and $\leqslant 5 \times$ normal & \multicolumn{2}{|r|}{$>5$} \\
\hline Persistent $\mathrm{RT}^{\mathrm{b}}$ & $<3$ days & 3-7 days & \multicolumn{2}{|r|}{$>7$ days } \\
\hline Ascites $^{\mathrm{b}}$ & Minimal & Moderate & \multicolumn{2}{|c|}{ Necessity for paracentesis (external drainage) } \\
\hline Bilirubin kinetics & & & \multicolumn{2}{|r|}{ Doubling within $48 \mathrm{~h}$} \\
\hline Coagulation & Normal & Normal & \multicolumn{2}{|r|}{$\begin{array}{l}\text { with need for replacement of } \\
\text { coagulation factors }\end{array}$} \\
\hline CNS & Normal & Normal & Normal & New onset cognitive impairment \\
\hline
\end{tabular}




\section{CONCLUSIONS}

By defining specific diagnostic and severity criteria for SOS/VOD in children, the group of EBMT experts aimed to overcome the weaknesses associated with the currently used criteria. This modification acknowledges both the pediatric-specific risk factors for SOS/VOD and the availability of an effective treatment option for children. Similar to the new EBMT criteria for adults, the group acknowledges that these proposals should be tested in daily practice and prospectively validated in clinical trials. These new criteria must stand the test of time and be periodically re-assessed, particularly biomarkers and imaging tools.

In summary, implementation of the proposed EBMT criteria for diagnosis and assessment of the severity of SOS/VOD will hopefully lead to earlier identification of patients in need of pre-emptive intervention with effective drugs for the treatment of SOS/VOD, and to the possibility of a predictive assessment of treatment effectiveness and outcome. ${ }^{94}$

\section{CONFLICT OF INTEREST}

The authors declare no conflict of interest.

\section{ACKNOWLEDGEMENTS}

Under the direction of the authors, Céline Tevlin, PhD, an employee of Elements Communications Ltd (part of the Obsidian Healthcare Group (OHG)), provided medical writing assistance for this manuscript. Editorial assistance was provided Fiona Jenkins, an employee of OHG. All authors received honoraria and/or research support from Jazz Pharmaceuticals whose product is discussed in this manuscript. Jazz Pharmaceuticals provided an unrestricted educational grant to support the current study, but did not participate in its execution, data/result analyses or manuscript writing.

\section{REFERENCES}

1 Boztug H, Sykora KW, Slatter M, Zecca M, Veys P, Lankester A et al. European Society for Blood and Marrow Transplantation analysis of treosulfan conditioning before hematopoietic stem cell transplantation in children and adolescents with hematological malignancies. Pediatr Blood Cancer 2016; 63: 139-148.

2 Helmy A. Review article: updates in the pathogenesis and therapy of hepatic sinusoidal obstruction syndrome. Aliment Pharmacol Ther 2006; 23: 11-25.

3 Fan CQ, Crawford JM. Sinusoidal obstruction syndrome (hepatic veno-occlusive disease). J Clin Exp Hepatol 2014; 4: 332-346.

4 Carreras E, Diaz-Ricart M. The role of the endothelium in the short-term complications of hematopoietic SCT. Bone Marrow Transplant 2011; 46: 1495-1502.

5 McKoy JM, Angelotta C, Bennett CL, Tallman MS, Wadleigh M, Evens AM et al. Gemtuzumab ozogamicin-associated sinusoidal obstructive syndrome (SOS): An overview from the research on adverse drug events and reports (RADAR) project. Leuk Res 2007; 31: 599-604.

6 Wadleigh M, Richardson PG, Zahrieh D, Lee SJ, Cutler C, Ho V et al. Prior gemtuzumab ozogamicin exposure significantly increases the risk of veno-occlusive disease in patients who undergo myeloablative allogeneic stem cell transplantation. Blood 2003; 102: 1578-1582.

7 Kebriaei P, Wilhelm K, Ravandi F, Brandt M, de Lima M, Ciurea S et al. Feasibility of allografting in patients with advanced acute lymphoblastic leukemia after salvage therapy with inotuzumab ozogamicin. Clin Lymphoma Myeloma Leuk 2013; 13: 296-301.

8 Cefalo MG, Maurizi P, Arlotta A, Scalzone M, Attina G, Ruggiero A et al. Hepatic veno-occlusive disease: a chemotherapy-related toxicity in children with malignancies. Paediatr Drugs 2010; 12: 277-284.

9 Cesaro S, Spiller M, Sartori MT, Alaggio R, Peruzzo M, Saggiorato G et al. Veno-occlusive disease in pediatric patients affected by Wilms tumor. Pediatr Blood Cancer 2011; 57: 258-261.

10 Nazemi KJ, Shen V, Finlay JL, Boyett J, Kocak M, Lafond D et al. High incidence of veno-ccclusive disease with myeloablative chemotherapy following craniospinal irradiation in children with newly diagnosed high-risk CNS embryonal tumors: a report from the Children's Oncology Group (CCG-99702). Pediatr Blood Cancer 2016; 63: 1563-1570.

11 Stork LC, Matloub Y, Broxson E, La M, Yanofsky R, Sather $H$ et al. Oral 6-mercaptopurine versus oral 6-thioguanine and veno-occlusive disease in children with standard-risk acute lymphoblastic leukemia: report of the Children's Oncology Group CCG-1952 clinical trial. Blood 2010; 115: 2740-2748.
12 Huezo-Diaz Curtis P, Uppugunduri CR, Muthukumaran J, Rezgui MA, Peters C, Bader $\mathrm{P}$ et al. Association of $\mathrm{CTH}$ variant with sinusoidal obstruction syndrome in children receiving intravenous busulfan and cyclophosphamide before hematopoietic stem cell transplantation. Pharmacogenomics $J$ (e-pub ahead of print 25 October 2016; doi: 10.1038/tpj.2016.65).

13 Seifert C, Wittig S, Arndt C, Gruhn B. Heparanase polymorphisms: influence on incidence of hepatic sinusoidal obstruction syndrome in children undergoing allogeneic hematopoietic stem cell transplantation. J Cancer Res Clin Oncol 2015; 141: 877-885.

14 Palomo M, Mir E, Rovira M, Escolar G, Carreras E, Diaz-Ricart M. What is going on between defibrotide and endothelial cells? Snapshots reveal the hot spots of their romance. Blood 2016; 127: 1719-1727.

15 Corbacioglu S, Cesaro S, Faraci M, Valteau-Couanet D, Gruhn B, Rovelli A et al. Defibrotide for prophylaxis of hepatic veno-occlusive disease in paediatric haemopoietic stem-cell transplantation: an open-label, phase 3, randomised controlled trial. Lancet 2012; 379: 1301-1309.

16 Coppell JA, Richardson PG, Soiffer R, Martin PL, Kernan NA, Chen A et al. Hepatic veno-occlusive disease following stem cell transplantation: incidence, clinical course, and outcome. Biol Blood Marrow Transplant 2010; 16: 157-168.

17 Richardson PG, Riches ML, Kernan NA, Brochstein JA, Mineishi S, Termuhlen AM et al. Phase 3 trial of defibrotide for the treatment of severe veno-occlusive disease and multi-organ failure. Blood 2016; 127: 1656-1665.

18 Lee JL, Gooley T, Bensinger W, Schiffman K, McDonald GB. Veno-occlusive disease of the liver after busulfan, melphalan, and thiotepa conditioning therapy: incidence, risk factors, and outcome. Biol Blood Marrow Transplant 1999; 5: 306-315.

19 Carreras E, Rosinol L, Terol MJ, Alegre A, de Arriba F, Garcia-Larana J et al. Veno-occlusive disease of the liver after high-dose cytoreductive therapy with busulfan and melphalan for autologous blood stem cell transplantation in multiple myeloma patients. Biol Blood Marrow Transplant 2007; 13: 1448-1454.

20 Akil A, Zhang Q, Mumaw CL, Raiker N, Yu J, Velez de Mendizabal N et al. Biomarkers for diagnosis and prognosis of sinusoidal obstruction syndrome after hematopoietic cell transplantation. Biol Blood Marrow Transplant 2015; 21: 1739-1745.

21 Iguchi A, Kobayashi R, Kaneda M, Kobayashi K. Plasma protein C is a useful clinical marker for hepatic veno-occlusive disease (VOD) in stem cell transplantation. Pediatr Blood Cancer 2010; 54: 437-443.

22 Cutler C, Kim HT, Ayanian S, Bradwin G, Revta C, Aldridge J et al. Prediction of veno-occlusive disease using biomarkers of endothelial injury. Biol Blood Marrow Transplant 2010; 16: 1180-1185.

23 Sartori MT, Spiezia L, Cesaro S, Messina C, Paris M, Pillon M et al. Role of fibrinolytic and clotting parameters in the diagnosis of liver veno-occlusive disease after hematopoietic stem cell transplantation in a pediatric population. Thromb Haemost 2005; 93: 682-689.

24 Tanikawa S, Mori S, Ohhashi K, Akiyama H, Sasaki T, Kaku H et al. Predictive markers for hepatic veno-occlusive disease after hematopoietic stem cell transplantation in adults: a prospective single center study. Bone Marrow Transplant 2000; 26: 881-886.

25 Mortele KJ, Van Vlierberghe H, Wiesner W, Ros PR. Hepatic veno-occlusive disease: MRI findings. Abdom Imaging 2002; 27: 523-526.

26 Lassau N, Auperin A, Leclere J, Bennaceur A, Valteau-Couanet D, Hartmann O. Prognostic value of doppler-ultrasonography in hepatic veno-occlusive disease. Transplantation 2002; 74: 60-66.

27 McCarville MB, Hoffer FA, Howard SC, Goloubeva O, Kauffman WM. Hepatic veno-occlusive disease in children undergoing bone-marrow transplantation: usefulness of sonographic findings. Pediatr Radiol 2001; 31: 102-105.

28 Jones RJ, Lee KS, Beschorner WE, Vogel VG, Grochow LB, Braine HG et al. Venoocclusive disease of the liver following bone marrow transplantation. Transplantation 1987; 44: 778-783.

29 McDonald GB, Sharma P, Matthews DE, Shulman HM, Thomas ED. Venocclusive disease of the liver after bone marrow transplantation: diagnosis, incidence, and predisposing factors. Hepatology 1984; 4: 116-122.

30 McDonald GB, Hinds MS, Fisher LD, Schoch HG, Wolford JL, Banaji M et al. Veno-occlusive disease of the liver and multiorgan failure after bone marrow transplantation: a cohort study of 355 patients. Ann Intern Med 1993; 118: 255-267.

31 Shulman HM, Hinterberger W. Hepatic veno-occlusive disease--liver toxicity syndrome after bone marrow transplantation. Bone Marrow Transplant 1992; 10: 197-214.

32 Mohty M, Malard F, Abecassis M, Aerts E, Alaskar AS, Aljurf M et al. Sinusoidal obstruction syndrome/veno-occlusive disease: current situation and perspectivesa position statement from the European Society for Blood and Marrow Transplantation (EBMT). Bone Marrow Transplant 2015; 50: 781-789.

33 Carreras E, Bertz H, Arcese W, Vernant JP, Tomas JF, Hagglund H et al. Incidence and outcome of hepatic veno-occlusive disease after blood or marrow transplantation: a prospective cohort study of the European Group for Blood and 
Marrow Transplantation. European Group for Blood and Marrow Transplantation Chronic Leukemia Working Party. Blood 1998; 92: 3599-3604.

34 Carreras E, Diaz-Beya M, Rosinol L, Martinez C, Fernandez-Aviles F, Rovira M. The incidence of veno-occlusive disease following allogeneic hematopoietic stem cell transplantation has diminished and the outcome improved over the last decade. Biol Blood Marrow Transplant 2011; 17: 1713-1720.

35 Yakushijin K, Atsuta Y, Doki N, Yokota A, Kanamori H, Miyamoto T et al. Sinusoidal obstruction syndrome after allogeneic hematopoietic stem cell transplantation: Incidence, risk factors and outcomes. Bone Marrow Transplant 2016; 51: 403-409.

36 Barker CC, Butzner JD, Anderson RA, Brant R, Sauve RS. Incidence, survival and risk factors for the development of veno-occlusive disease in pediatric hematopoietic stem cell transplant recipients. Bone Marrow Transplant 2003; 32: 79-87.

37 Cesaro S, Pillon M, Talenti E, Toffolutti T, Calore E, Tridello G et al. A prospective survey on incidence, risk factors and therapy of hepatic veno-occlusive disease in children after hematopoietic stem cell transplantation. Haematologica 2005; 90 : 1396-1404.

38 Corbacioglu S, Honig M, Lahr G, Stohr S, Berry G, Friedrich W et al. Stem cell transplantation in children with infantile osteopetrosis is associated with a high incidence of VOD, which could be prevented with defibrotide. Bone Marrow Transplant 2006; 38: 547-553.

39 Richardson PG, Elias AD, Krishnan A, Wheeler C, Nath R, Hoppensteadt D et al. Treatment of severe veno-occlusive disease with defibrotide: compassionate use results in response without significant toxicity in a high-risk population. Blood 1998; 92: 737-744.

40 Richardson PG, Murakami C, Jin Z, Warren DL, Momtaz P, Hoppensteadt D et al. Multi-institutional use of defibrotide in 88 patients post stem cell transplant with severe veno-occlusive disease and multi-system organ failure; response without significant toxicity in a high risk population and factors predictive of outcome. Blood 2002; 100: 4337-4343.

41 Richardson PG, Soiffer RJ, Antin JH, Uno H, Jin Z, Kurtzberg J et al. Defibrotide for the treatment of severe hepatic veno-occlusive disease and multi-organ failure post stem cell transplantation: a multi-center, randomized, dose-finding trial. Biol Blood Marrow Transplant 2010; 16: 1005-1017.

42 Zhang L, Wang $\mathrm{Y}$, Huang $\mathrm{H}$. Defibrotide for the prevention of hepatic veno-occlusive disease after hematopoietic stem cell transplantation: a systematic review. Clin Transplant 2012; 26: 511-519.

43 Dignan F, Gujral D, Ethell M, Evans S, Treleaven J, Morgan G et al. Prophylactic defibrotide in allogeneic stem cell transplantation: minimal morbidity and zero mortality from veno-occlusive disease. Bone Marrow Transplant 2007; 40: 79-82.

44 Versluys B, Bhattacharaya R, Steward C, Cornish J, Oakhill A, Goulden N. Prophylaxis with defibrotide prevents veno-occlusive disease in stem cell transplantation after gemtuzumab ozogamicin exposure. Blood 2004; 103: 1968.

45 Chalandon $Y$, Roosnek E, Mermillod B, Newton A, Ozsahin H, Wacker $\mathrm{P}$ et al. Prevention of veno-occlusive disease with defibrotide after allogeneic stem cell transplantation. Biol Blood Marrow Transplant 2004; 10: 347-354.

46 Richardson P, Smith A, Triplett B, Kernan N, Grupp S, Antin J et al. Treatment of hepatic veno-occlusive disease/sinusoidal obstruction syndrome (VOD/SOS) post-hematopoietic stem cell transplantation (HSCT) in patients with acute leukemias: a subgroup analysis from the defibrotide expanded-access program ASH. Annual Meeting Abstracts 2016; 128: 3412.

47 Corbacioglu S, Carreras E, Mohty M, Pagliuca A, Boelens JJ, Damaj G et al. Defibrotide for the treatment of hepatic veno-occlusive disease: final results from the international compassionate-use program. Biol Blood Marrow Transplant 2016; 22: $1874-1882$

48 Corbacioglu S, Greil J, Peters C, Wulffraat N, Laws HJ, Dilloo D et al. Defibrotide in the treatment of children with veno-occlusive disease (VOD): a retrospective multicentre study demonstrates therapeutic efficacy upon early intervention. Bone Marrow Transplant 2004; 33: 189-195.

49 Grupp S, Smith A, Triplett B, Kernan N, Antin J, Lehmann L et al. Timingof initiation of defibrotide post-diagnosis of hepatic veno-occlusive disease/sinusoidal obstruction syndrome post-hematopoietic stem cell transplantation: exploratory age-group analysis from an expanded access study. ASH, Annual Meeting Abstracts 2016; 128: 66

50 Mohty M, Malard F, Abecassis M, Aerts E, Alaskar AS, Aljurf M et al. Revised diagnosis and severity criteria for sinusoidal obstruction syndrome/veno-occlusive disease in adult patients: a new classification from the European Society for Blood and Marrow Transplantation. Bone Marrow Transplant 2016; 51: 906-912.

51 Hogan WJ, Maris M, Storer B, Sandmaier BM, Maloney DG, Schoch HG et al. Hepatic injury after nonmyeloablative conditioning followed by allogeneic hematopoietic cell transplantation: a study of 193 patients. Blood 2004; 103: 78-84.

52 Nagler A, Labopin M, Berger R, Bunjes D, Campos A, Socie G et al. Allogeneic hematopoietic $S C T$ for adults $A M L$ using i.v. $B U$ in the conditioning regimen: outcomes and risk factors for the occurrence of hepatic sinusoidal obstructive syndrome. Bone Marrow Transplant 2014; 49: 628-633.
53 Bartelink IH, Lalmohamed A, van Reij EM, Dvorak CC, Savic RM, Zwaveling J et al. Association of busulfan exposure with survival and toxicity after haemopoietic cell transplantation in children and young adults: a multicentre, retrospective cohort analysis. Lancet Haematol 2016; 3: e526-e536.

54 Uppugunduri CR, Rezgui MA, Diaz PH, Tyagi AK, Rousseau J, Daali Y et al. The association of cytochrome P450 genetic polymorphisms with sulfolane formation and the efficacy of a busulfan-based conditioning regimen in pediatric patients undergoing hematopoietic stem cell transplantation. Pharmacogenomics J 2014; 14: 263-271.

55 Bredeson C, LeRademacher J, Kato K, Dipersio JF, Agura E, Devine SM et al. Prospective cohort study comparing intravenous busulfan to total body irradiation in hematopoietic cell transplantation. Blood 2013; 122: 3871-3878.

56 Okamoto Y, Nagatoshi Y, Kosaka Y, Kikuchi A, Kato S, Kigasawa H et al. Prospective pharmacokinetic study of intravenous busulfan in hematopoietic stem cell transplantation in 25 children. Pediatr Transplant 2014; 18: 294-301.

57 Malar R, Sjoo F, Rentsch K, Hassan M, Gungor T. Therapeutic drug monitoring is essential for intravenous busulfan therapy in pediatric hematopoietic stem cell recipients. Pediatr Transplant 2011; 15: 580-588.

58 Veal GJ, Nguyen L, Paci A, Riggi M, Amiel M, Valteau-Couanet D et al. Busulfan pharmacokinetics following intravenous and oral dosing regimens in children receiving high-dose myeloablative chemotherapy for high-risk neuroblastoma as part of the HR-NBL-1/SIOPEN trial. Eur J Cancer 2012; 48: 3063-3072.

59 Schulz AS, Classen CF, Mihatsch WA, Sigl-Kraetzig M, Wiesneth M, Debatin KM et al. HLA-haploidentical blood progenitor cell transplantation in osteopetrosis. Blood 2002; 99: 3458-3460.

60 Ouachee-Chardin M, Elie C, de Saint Basile G, Le Deist F, Mahlaoui N, Picard C et al. Hematopoietic stem cell transplantation in hemophagocytic lymphohistiocytosis: a single-center report of 48 patients. Pediatrics 2006; 117: e743-e750.

61 Cheuk DK, Wang P, Lee TL, Chiang AK, Ha SY, Lau YL et al. Risk factors and mortality predictors of hepatic veno-occlusive disease after pediatric hematopoietic stem cell transplantation. Bone Marrow Transplant 2007; 40: 935-944.

62 Li CK, Shing MM, Chik KW, Lee V, Leung TF, Cheung AY et al. Haematopoietic stem cell transplantation for thalassaemia major in Hong Kong: prognostic factors and outcome. Bone Marrow Transplant 2002; 29: 101-105.

63 Mathews V, George B, Deotare U, Lakshmi KM, Viswabandya A, Daniel D et al. A new stratification strategy that identifies a subset of class III patients with an adverse prognosis among children with beta thalassemia major undergoing a matched related allogeneic stem cell transplantation. Biol Blood Marrow Transplant 2007; 13: 889-894.

64 Horn B, Reiss U, Matthay K, McMillan A, Cowan M. Veno-occlusive disease of the liver in children with solid tumors undergoing autologous hematopoietic progenitor cell transplantation: a high incidence in patients with neuroblastoma. Bone Marrow Transplant 2002; 29: 409-415.

65 Qayed M, Chiang KY, Ricketts R, Alazraki A, Tahvildari A, Haight A et al. Tandem stem cell rescue as consolidation therapy for high-risk neuroblastoma. Pediatr Blood Cancer 2012; 58: 448-452.

66 Yasui N, Kawamoto H, Fujiwara M, Aihara Y, Ogawa C, Hosono A et al. High-dose chemotherapy for high-risk retinoblastoma: clinical course and outcome of 14 cases in the National Cancer Center, Japan. Bone Marrow Transplant 2015; 50: 221-224.

67 Elli M, Pinarli FG, Dagdemir A, Acar S. Veno-occlusive disease of the liver in a child after chemotherapy for brain tumor. Pediatr Blood Cancer 2006; 46: 521-523.

68 Sulis ML, Bessmertny O, Granowetter L, Weiner M, Kelly KM. Veno-occlusive disease in pediatric patients receiving actinomycin $D$ and vincristine only for the treatment of rhabdomyosarcoma. J Pediatr Hematol Oncol 2004; 26: 843-846.

69 Czauderna P, Katski K, Kowalczyk J, Kurylak A, Lopatka B, Skotnicka-Klonowicz G et al. Venoocclusive liver disease (VOD) as a complication of Wilms' tumour management in the series of consecutive 206 patients. Eur J Pediatr Surg 2000; 10: 300-303.

70 Schechter T, Finkelstein Y, Doyle J, Verjee Z, Moretti M, Koren G et al. Pharmacokinetic disposition and clinical outcomes in infants and children receiving intravenous busulfan for allogeneic hematopoietic stem cell transplantation. Biol Blood Marrow Transplant 2007; 13: 307-314.

71 Toh HC, McAfee SL, Sackstein R, Cox BF, Colby C, Spitzer TR. Late onset veno-occlusive disease following high-dose chemotherapy and stem cell transplantation. Bone Marrow Transplant 1999; 24: 891-895.

72 Pai RK, van Besien K, Hart J, Artz AS, O'Donnell PH. Clinicopathologic features of late-onset veno-occlusive disease/sinusoidal obstruction syndrome after high dose intravenous busulfan and hematopoietic cell transplant. Leuk Lymphoma 2012; 53: 1552-1557.

73 Myers KC, Dandoy C, El-Bietar J, Davies SM, Jodele S. Veno-occlusive disease of the liver in the absence of elevation in bilirubin in pediatric patients after hematopoietic stem cell transplantation. Biol Blood Marrow Transplant 2015; 21: 379-381 
74 Naples J, Skeens M, Bajwa R. Anicteric hepatic veno-occlusive disease after hematopoietic stem cell transplantation in children. Blood 2014; 124: 5849-5849.

75 Carreras E. How I manage sinusoidal obstruction syndrome after haematopoietic cell transplantation. Br J Haematol 2015; 168: 481-491.

76 Carreras E, Granena A, Navasa M, Bruguera M, Marco V, Sierra J et al. On the reliability of clinical criteria for the diagnosis of hepatic veno-occlusive disease. Ann Hematol 1993; 66: 77-80.

77 Hod E, Schwartz J. Platelet transfusion refractoriness. Br J Haematol 2008; 142 348-360.

78 Rio B, Andreu G, Nicod A, Arrago JP, Dutrillaux F, Samama $M$ et al. Thrombocytopenia in venocclusive disease after bone marrow transplantation or chemotherapy. Blood 1986; 67: 1773-1776.

79 Bearman SI. The syndrome of hepatic veno-occlusive disease after marrow transplantation. Blood 1995; 85: 3005-3020.

80 Nash RA, Gooley T, Davis C, Appelbaum FR. The problem of thrombocytopenia after hematopoietic stem cell transplantation. Oncologist 1996; 1: 371-380.

81 Norol F, Kuentz M, Cordonnier C, Beaujean F, Haiouin C, Vernant JP et al. [Influence of clinical status on the efficacy of stored platelet transfusion]. Rev $\mathrm{Fr}$ Transfus Hemobiol 1993; 36: 427-437.

82 Hommeyer SC, Teefey SA, Jacobson AF, Higano CS, Bianco JA, Colacurcio CJ et al. Venocclusive disease of the liver: prospective study of US evaluation. Radiology 1992; 184: 683-686.

83 Mahgerefteh SY, Sosna J, Bogot N, Shapira MY, Pappo O, Bloom Al. Radiologic imaging and intervention for gastrointestinal and hepatic complications of hematopoietic stem cell transplantation. Radiology 2011; 258: 660-671.

84 Carreras E, Granena A, Navasa M, Bruquera M, Marco V, Sierra J et al. Transjugular liver biopsy in BMT. Bone Marrow Transplant 1993; 11: 21-26.

85 Shulman HM, Gooley T, Dudley MD, Kofler T, Feldman R, Dwyer D et al. Utility of transvenous liver biopsies and wedged hepatic venous pressure measurements in sixty marrow transplant recipients. Transplantation 1995; 59: 1015-1022.

86 Teefey SA, Brink JA, Borson RA, Middleton WD. Diagnosis of venoocclusive disease of the liver after bone marrow transplantation: value of duplex sonography. $A J R$ Am J Roentgenol 1995; 164: 1397-1401.

87 Sharafuddin MJ, Foshager MC, Steinbuch M, Weisdorf DJ, Hunter DW. Sonographic findings in bone marrow transplant patients with symptomatic hepatic venoocclusive disease. J Ultrasound Med 1997; 16: 575-586.
88 Kriegshauser JS, Charboneau JW, Letendre L. Hepatic venocclusive disease after bone-marrow transplantation: diagnosis with duplex sonography. $A J R A m J$ Roentgenol 1988; 150: 289-290.

89 Hashiguchi M, Okamura T, Yoshimoto K, Ono N, Imamura R, Yakushiji K et al. Demonstration of reversed flow in segmental branches of the portal vein with hand-held color Doppler ultrasonography after hematopoietic stem cell transplantation. Bone Marrow Transplant 2005; 36: 1071-1075.

90 Skeens MA, McArthur J, Cheifetz IM, Duncan C, Randolph AG, Stanek J et al. Highvariability in the reported management of hepatic veno-occlusive disease in children after hematopoietic stem cell transplantation. Biol Blood Marrow Transplant 2016; 22: 1823-1828.

91 Oshrine B, Lehmann LE, Duncan CN. Safety and utility of liver biopsy after pediatric hematopoietic stem cell transplantation. J Pediatr Hematol Oncol 2011; 33: e92-e97.

92 Chao N. How I treat sinusoidal obstruction syndrome. Blood 2014; 123 4023-4026.

93 Bearman SI, Anderson GL, Mori M, Hinds MS, Shulman HM, McDonald GB. Venoocclusive disease of the liver: development of a model for predicting fatal outcome after marrow transplantation. I Clin Oncol 1993; 11: 1729-1736.

94 Dignan FL, Wynn RF, Hadzic N, Karani J, Quaglia A, Pagliuca A et al. BCSH/BSBMT guideline: diagnosis and management of veno-occlusive disease (sinusoidal obstruction syndrome) following haematopoietic stem cell transplantation. $\mathrm{Br} \mathrm{J}$ Haematol 2013; 163: 444-457.

This work is licensed under a Creative Commons Attribution 4.0 International License. The images or other third party material in this article are included in the article's Creative Commons license, unless indicated otherwise in the credit line; if the material is not included under the Creative Commons license, users will need to obtain permission from the license holder to reproduce the material. To view a copy of this license, visit http://creativecommons.org/licenses/ by/4.0/

(c) The Author(s) 2018 